\title{
CONSTRUCCIONES AGRARIAS EN MADERA: UNA VENTAJA EN LA INTEGRACIÓN EN EL PAISAJE
}

\author{
(WOODEN RURAL BUILDINGS: AN ADVENTAGE IN LANDSCAPING)
}

Ignacio Cañas Guerrero, Gabriel Cañas Guerrero y Francisco Ayuga Téllez

Dpto. de Construcción y Vias Rurales

E.T.S.I. Agrónomos - Ciudad Universitaria

MADRID - ESPAÑA

Fecha de recepción: $25 \times \times \cdot 90$

\section{RESUMEN}

La conservación de los valores estéticos del paisaje cobran cada dia más importancia; en este aspecto las construcciones en madera aportan una serie de ventajas.

Para analizar el impacto de las construcciones contamos con dos métodos: Sintético y Analítico.

En el primero, basado en el estudio de pares de fotografias, encontramos que la madera tiene una serie de ventajas: es un material natural, ofrece una variedad de colores y texturas, posee confortabilidad visual, auditiva, táctil, olfativa y gustativa, intervienen favorablemente factores sicológicos, se provoca un menor impacto paisajistico a la hora del montaje con un envejecimiento más noble y, llegado el momento, una mayor facilidad para su demolición.

El Analitico, sin embargo, se basa en el estudio de los com. ponentes físicos y estéticos. Dentro de los componentes físicos se consideran los materiales, los cerramientos y la distribución de los edificios y obras accesorias. En los componentes estéticos hablamos de la forma, la escala, la linea y el color en primer término y sequidamente de la textura y las posibilidades de la madera en este aspecto: textura propia por el acabado, el tratamiento y la colocación de los tableros.

\section{SUMMARY}

Aesthetic values conservation are more important every day. Wooden constructions are better for this conservation.

Construction impact on landscape can be analyzed by two ways: Synthetic and Analytic methods.

Using at first a list of wood adventages (based in comparing photographs) can be found. It is a natural material and it can be selected a great kind of textures and colours, visual, auditory, tactile, smelling and gustative comfort is provided. Psychological factors are in favour of wooden constructions. Assembling and demolition cause less landscape impact.

Nevertheless, Analytic method are based on physics and aesthetics components analysis. Physics components are walls materials, buildings distribution and services in

buildings. Aesthetics components are shape, sacale, line and colour in a first group and texture in a second. Otherwise the texture wood has different posibilities, its own nature, finished treatement and boards position.

\section{INTRODUCCIÓN}

Durante los últimos 50 años, la presión ejercida sobre el medio ha excedido la capacidad de acogida de éste, lo que ha originado problemas tales como erosión, polución, etc. Ante este hecho surge la necesidad de estudiar de modo coherente y minucioso todos estos fenómenos, y su repercusión en el medio y, por extensión, en el hombre.
En una primera fase se prestó mayor atención a los problemas referentes a la contaminación por resultar sus efectos más patentes a corto plazo, y en esta linea se han desarrollado numerosos estudios. Sin embargo, hoy dia se ha puesto de manifiesto que no es éste el único punto conflictivo: los sistemas naturales han de ser analizados en profundidad, tomandō en consideración cada uno de sus elementos para Tegar a una ordenación que garantice el mantenimiento del equilibrio. 
De hecho, el hombre al gestionar la naturaleza persigue dos propósitos básicos, a saber:

$1^{\circ}$ Obtener ciertos artículos tangibles o productos de la tierra como son agua, suelo, madera, etc.

$2^{\circ}$ Obtener productos intangibles, siendo su valor estético, visual o simbólico lo que aprovecha el hombre. Este segundo fin es el que hoy día emerge, y en donde el paisaje juega un papel esencial.

Estos valores simbólicos o estéticos cobran cada día más importancia; en este aspecto las construcciones en madera pueden ayudarnos, en algunos casos, a la conservación del paisaje natural.

En otra publicación sobre "Método mixto de estimación del impacto paisajístico de la construcción", se analizará una metodología general para la integración de las construcciones en el paisaje. En este articulo nos proponemos aplicar ese método para el caso de las construcciones de madera. Al hablar de construcciones en madera nos estamos refiriendo en esta publicación a aquellas construcciones en cuya fachada interviene principalmente la madera.

El esquema que se propondrá en dicha publicación, para el análisis del impacto paisajistico, aparece en el Cuadro n. 1.

CUADRO 1.:Método de estimación del impacto paisajístico.

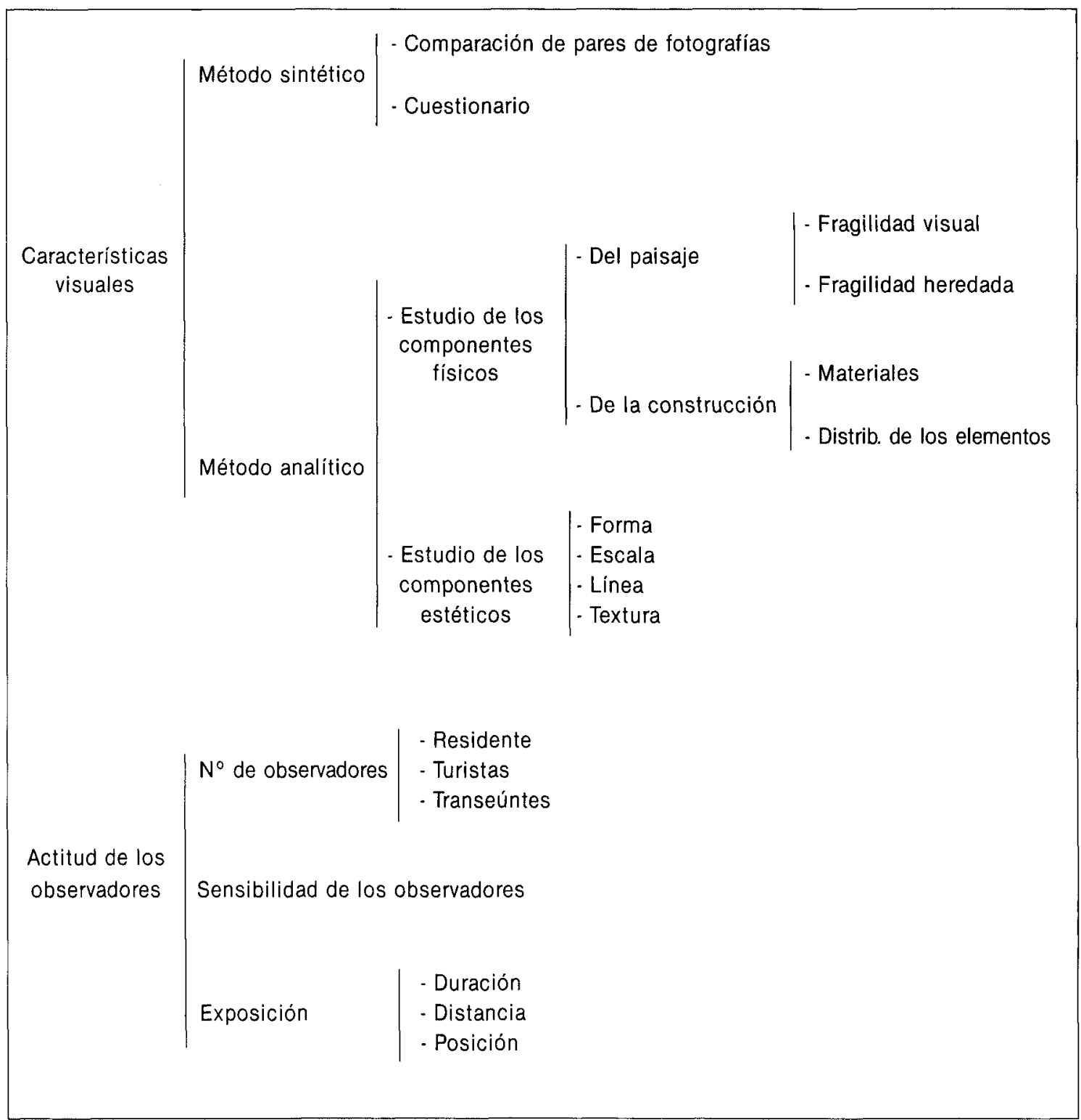




\section{TIPO DE CONSTRUCCIONES $Y$ ANALISIS DE IMPACTO}

En el cuadro $N^{\circ} 2$ aparecen las principales construcciones agrarias en las que puede utilizarse, como elemento de fachada, la madera. De ellas las más importantes son los alojamientos de ganado, almacenes y viviendas. Los que más dificultad presentan para la integración son los almacenes y los alojamientos de ganado, ya que suelen presentar problemas de escala con relación a las construcciones tradicionales; además, la utilización de materiales como el fibrocemento o la utilización abusiva de placas metálicas y otros elementos con texturas y colores poco naturales suelen causar impacto negativo. En las viviendas el problema suele ser menor: por una parte el componente escala no plantea habitualmente problemas, y por otra los propietarios suelen poner interés en los materiales y tipologías, de forma que no desentonen mucho del resto de las viviendas ya construidas $y$, de forma indirecta, con el recurso paisajístico.

Por ser los almacenes y alojamientos de ganado los que más problemas presentan son a los que principalmente nos vamos a referir en este estudio. Nos centraremos en las características visuales, no estudiando la actitud de los observadores, ya que este último requeriria centrarse en una zona concreta.

\section{CUADRO 2. Utilización de la madera para construcciones agrarias.}

\begin{tabular}{|lc|}
\hline Construcciones & Utilización madera \\
\hline Industrias Agroalimentarias & $*$ \\
Mercados en origen & $*$ \\
Alojamientos de ganado & $*$ \\
Almacenes & $*$ \\
Graneros & $*$ \\
Centros de bombeo & \\
Centros de Transformación & \\
Invernaderos & \\
Caminos Rurales & $*$ \\
Presas y Azudes & $*$ \\
Canales y Acequias & \\
Drenes & $*$ \\
Puentes & \\
Depuración de aguas & $*$ \\
Depósitos de liquidos & $*$ \\
Silos & $*$ \\
Cercas & $*$ \\
Cortavientos & \\
Vivienda & \\
Dependencias agrícolas & \\
\hline
\end{tabular}

Pasemos a analizar, de acuerdo con el esquema expuesto en el cuadro $n^{\circ} 1$, las características visuales de las construcciones de madera. Empecemos viendo el método sintético para después pasar al método analítico.

\section{APLICACIÓN DEL MÉTODO SINTÉTICO}

El estudio de pares de fotografias, comparando las diversas posibilidades debería realizarse para una zona concreta y una determinada construcción. Aqui consideraremos el estudio en general, con lo que nos limitaremos a señalar la predisposición que se tiene a pensar que las construcciones de madera presentan una serie de ventajas sobre otros materiales estandarizados, como son el fibrocemento o los bloques prefabricados de hormigón o, incluso, a veces sobre el mismo ladrillo. Entre los aspectos positivos a la hora de integrar la construcción de madera en el paisaje podemos citar:

- Es un material natural, con lo que su integración en el paisaje no suele presentar problemas. Puede objetarse que necesita más cuidados que los otros materiales, como es el barnizado o pintado cada un cierto número de años. Esto es cierto, pero cualquier "material vivo" necesita unos cuidados especiales, como son los animales o las plantas.

- Tiene una variación en colores y texturas, que rompen la monotonía y es precisamente esto una de las características que diferencia los materiales "artificiales" de los "naturales", asi una plancha de fibrocemento es absolutamente uniforme y lo mismo sucede con los metales. Esto contrasta con la naturaleza que siempre presenta variaciones: no todos los árboles son iguales, ni siquiera todos los chopos, las piedras y demás elementos no poseen una única tonalidad. Es éste uno de los motivos por los que al utilizar ciertos materiales dan la sensación de intrusismo.

- La madera presenta además un componente fuerte de confortabilidad. Nos referimos al término confortabilidad como opuesto de frialdad. Esto lo percibimos por todos los sentidos, asi tenemos:

Confortabilidad visual. En efecto, la madera tiene tonalidades amarillas, anaranjadas, marrones y rojizas, que son las que desde el punto de vista de colores denominamos colores cálidos, frente a los colores frios como son las tonalidades azules.

Confortabilidad táctil. Es una experiencia que todos tenemos. La percibimos por ejemplo en los suelos de madera, que conservan la temperatura del interior o su propia elasticidad que amortiguan los impactos, cosas que no suceden, por ejemplo, o con suelos de piedra, cerámica, etc. 

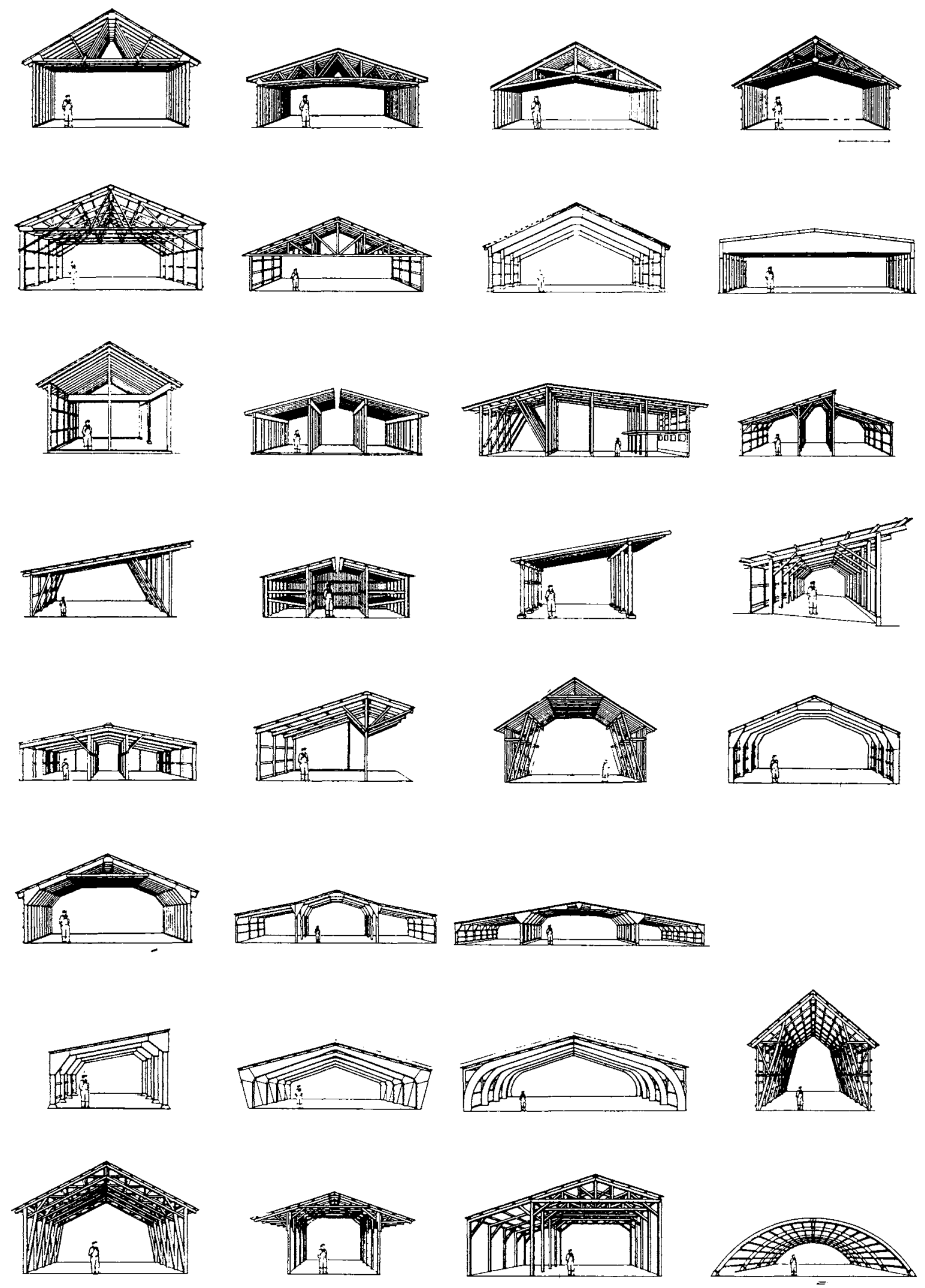

Fig. 1. El diseño de la estructura nos va a determinar la forma del edificio. En esta figura aparecen representados los principales tipos de estructuras utilizados en Europa. Todos ellos son de madera. Fuente: Dolby et al 1988 


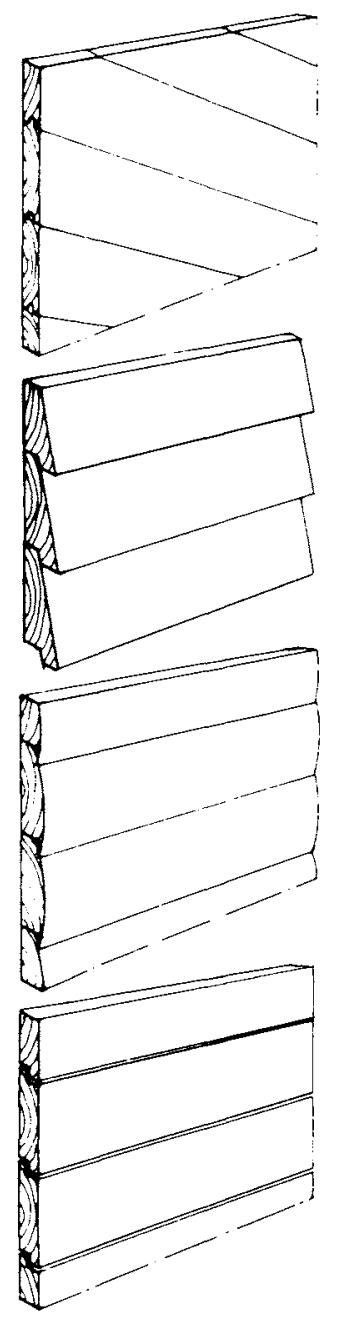

Tablero junto inclinado

Tablero solapado recto horizontal

Tablero solapado curvo horizontal

Tablero con rebaje horizontal

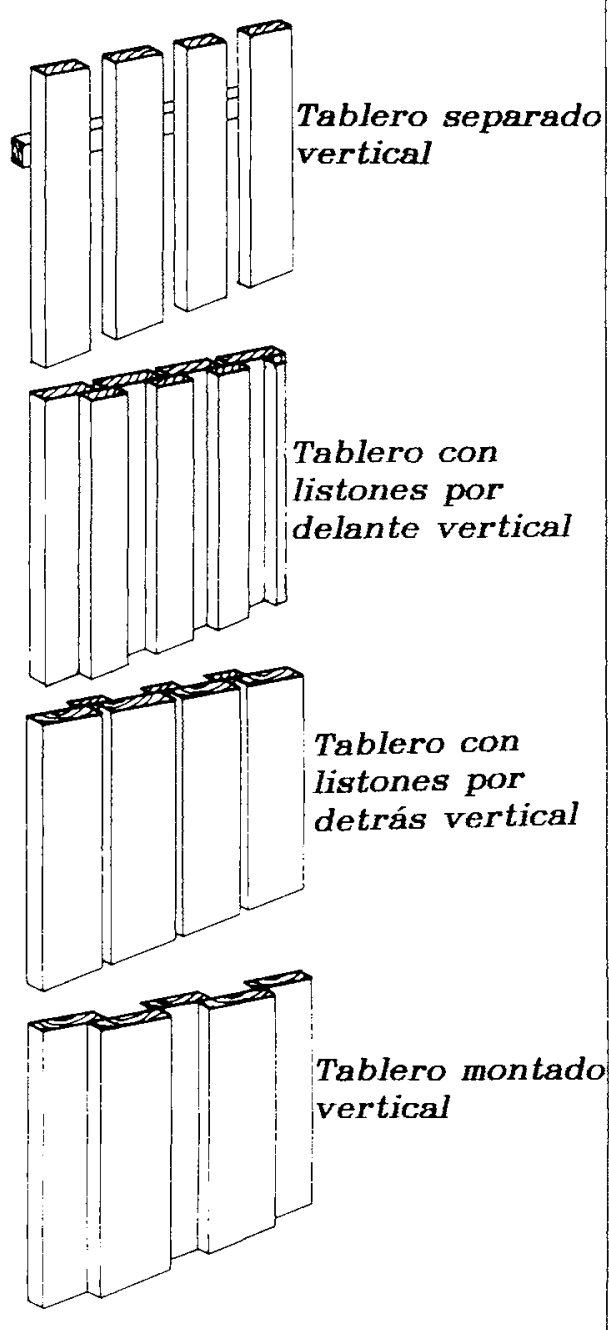

Fig. 2. Los distintos tipos de orientación y disposición de los tableros modifican la textura. Hay tres tipos de orientación: vertical, horizontal e inclinada. Dentro de cada uno de éstos hay varias disposiciones, asi están: Tableros juntos que pueden estar unidos o solapados; a su vez los solapados pueden ser recto o curvo. Tableros separados. Tableros cubiertos con listones, que pueden estar cubiertos por delante o por detrás. Tableros montados. Tableros con rebaje. Dolby et al 1988

Confortabilidad auditiva. Se puede notar cuando tenemos paredes de madera, que la absorbencia de ésta suele eliminar el eco propio de las habitaciones de piedra o vacias.

Confortabilidad olfativa y gustativa. Los edificios donde abundan los elementos de madera suelen tener olores típicos a madera, olores de roble, nogal o a "viejo".

A la hora de integrarlo en el resto del paisaje podemos jugar con las inclinaciones de los tablones. Es muy dis. tinto ponerlos verticales que horizontales, o los tipicos inclinados de las puertas, con ello estamos rompiendo la uniformidad tan característica de los elementos industriales. Esta variación la podemos ayudar con distintos tipos de madera, distintos barnices o, incluso, distintos acabados (pulido, escobillado, lijado grueso, etc.)

La madera nos permite jugar con elementos rústicos, dando un carácter típicamente campestre. Piénsese, por ejemplo, en los establos en los que hay una separación entre tablas para permitir la ventilación, o en las estructuras vistas de troncos, que siendo de precio muy interesantes suelen permitirnos una conexión con las tipologias tradicionales.

- Hay además otros elementos de tipo sicológico, por los que asociamos las construcciones de madera a una integración con el paisaje. Por una parte, et hecho de que sea un material natural lo asociamosenseguida con el árbol. Es lo que los artistas Ilamarian un diálogo entre el edificio y su entorno. 


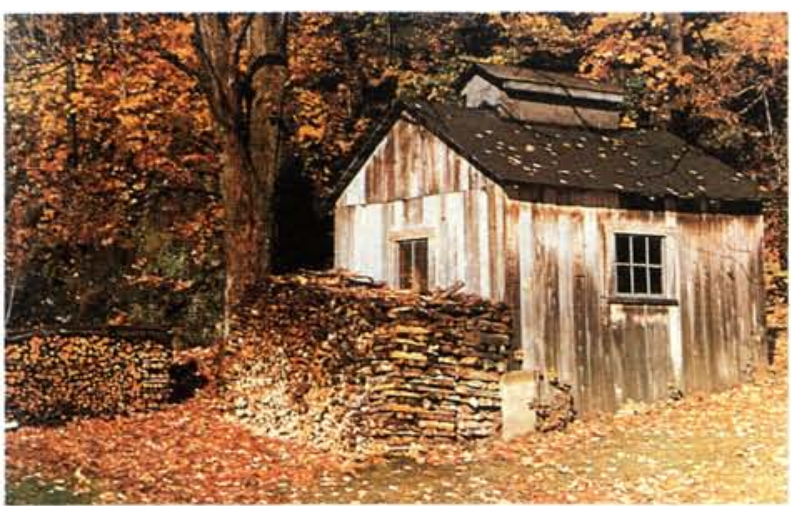

Fig. 3. Una de las ventajas que presentan las construcciones de ma dera es que en edificios semiabandonados pueden adquirir un cierto encanto. Suzi Forbes 1985.

- Hay otro componente que se suele asociar a la calidad, recordándonos quizá muebles o piezas de arte. Puede a simple vista parecer poco importante este hecho, pero el factor de simbolismo es fundamental a la hora de considerar la integración de cualquier estructura en el paisaje. En Estados Unidos ya se han dado varios problemas de este tipo, al poner centrales nucleares en zonas que se ven desde paradores nacionales, aunque se intenten diseñar con una forma adecuada; aunque se elijan colores correctos no dejará de ser una central nuclear con todo el efecto sicológico que esto conlleva. Cuando se hizo un estudio sobre el impacto de la central nuclear de Greene County, el efecto más destacado de todos los estudios fue el sicoló. gico. Asi, durante las encuestas se vio que los habitantes pensaban que, de ponerse la central, la zona perderia su carácter; alguno respondió que pasaria lo mismo que si desde Versalles se pudiese ver una central nuclear...

Otra de las ventajas que presentan los edificios de madera es que, cuando pasa la vida útil, tienen una cierta facilidad para demolerlo. Es penoso ver, en parajes más o menos interesantes, edificios en ruinas que es dificil darles alguna utilidad. Con los edificios de madera estos problemas disminuyen, ya que incluso edificios de madera abandonados pueden tener su encanto, como se observa en la Fig. 3.

Las construcciones de madera, en relación con el tiempo, suelen adquirir un cierto atractivo como puede verse en las figs. 4 y 5 . Ésta es una de las diferencias frente a otros elementos convencionales, ya que con el tiem. po puede ganar prestancia.

Para la integración en el paisaje de una edificación hay que tener en cuenta también el impacto que causa a la hora de la instalación; frente a construcciones de hormigón, etc., presentan la ventaja de que durante su montaje apenas tienen impacto negativo.

(c) Consejo Superior de Investigaciones Científicas Licencia Creative Commons 3.0 España (by-nc)
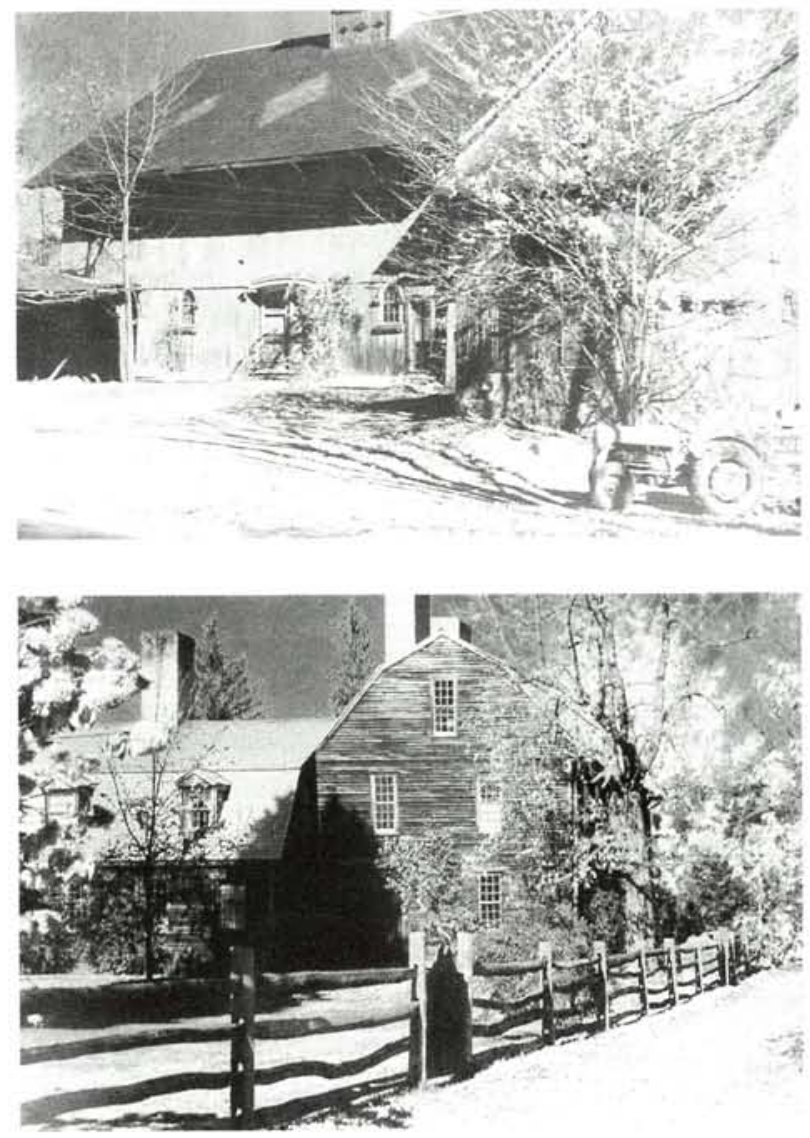

Figs. 4 y 5. Las construcciones en madera, al contrario de lo que su. cede en la mayor parte de los materiales convencionales, con el tiem. po pueden adquirir unas caracteristicas estéticas mejores que las que tenian en un principio. Suzi Forbes 1985.

\section{APLICACIÓN DEL MÉTODO ANALÍTICO}

Se ha seguido el esquema del cuadro 1, aunque por cuestiones de espacio sólo se tratarán los factores más generales, ya que muchos de ellos exigen conocer el tipo de instalación exacta con sus necesidades y el paisaje adyacente, con el fin de establecer unas relaciones concretas. Estudiaremos, primero, los componentes físicos de la construcción y pasaremos, después, al estudio de componentes estéticos de la construc. ción en madera.

\section{ESTUDIO DE LOS COMPONENTES FISICOS DE LA CONSTRUCCIÓN}

\subsection{Los materiales}

En España hay poca tradición de utilizar madera, por ello las variedades de madera que se traen son bastante limitadas. En la práctica no se utilizan más de 20 tipos, considerando todos los usos de maderas.

http://informesdelaconstruccion.revistas.csic.es 
CUADRO 3. Maderas utilizadas en carpinteria exterior.

\begin{tabular}{|c|c|c|}
\hline $\begin{array}{l}\text { - Afrormosia } \\
\text { - Afzelia } \\
\text { - Alerce Europeo } \\
\text { - Andiroba } \\
\text { - Bilinga Aloma } \\
\text { - Bolondo } \\
\text { - Bubinga } \\
\text { - Bosse, Eyo } \\
\text { - Caoba Americana } \\
\text { - Cedro Rojo del Pacifico } \\
\text { - Cedro } \\
\text { - Coral } \\
\text { - Danta } \\
\text { - Framire } \\
\text { - Freijo } \\
\text { - Ipe } \\
\text { - Iroko } \\
\text { - Kapur } \\
\text { - Keruing/Gurjun } \\
\text { - Merbau } \\
\text { - Mongoy } \\
\text { - Niangon }\end{array}$ & $\begin{array}{l}\text { Necesitan } \\
\text { tratamiento: }\end{array}$ & $\begin{array}{l}\text { - Nogal Africano } \\
\text { - Nyatoh } \\
\text { - Okola } \\
\text { - Panga o Wenge } \\
\text { - Picea Canadiense } \\
\text { - Pino Maritimo } \\
\text { - Pino Melix } \\
\text { - Pino Oregón } \\
\text { - Roble Europeo } \\
\text { - Samanguila } \\
\text { - Sapeli } \\
\text { - Teca } \\
\text { - Tola Blanca } \\
\text { - Trama Kalungi } \\
\text { - Utile, Sipo } \\
\text { - Abeto } \\
\text { - Mengkulang } \\
\text { - Meranti Rojo Obscuro } \\
\text { - Meranti Rojo Claro } \\
\text { - Pino Albar } \\
\text { - Pino Amarillo } \\
\text { - Tsuga }\end{array}$ \\
\hline
\end{tabular}

En el cuadro 3 se han recogido las principales maderas que pueden utilizarse en el exterior; también se han señalado las que normalmente necesitan tratamiento, aunque, como es evidente, dependerá de la zona.

\subsection{Distribución de los diversos elementos}

\subsubsection{Los edificios}

Como ya se ha expuesto, una de las ventajas que presenta la madera es que da a las fachadaș una variedad interesante. Esto es especialmente necesario en edificios como almacenes o alojamientos de ganado.

Suzi Forbes 1985
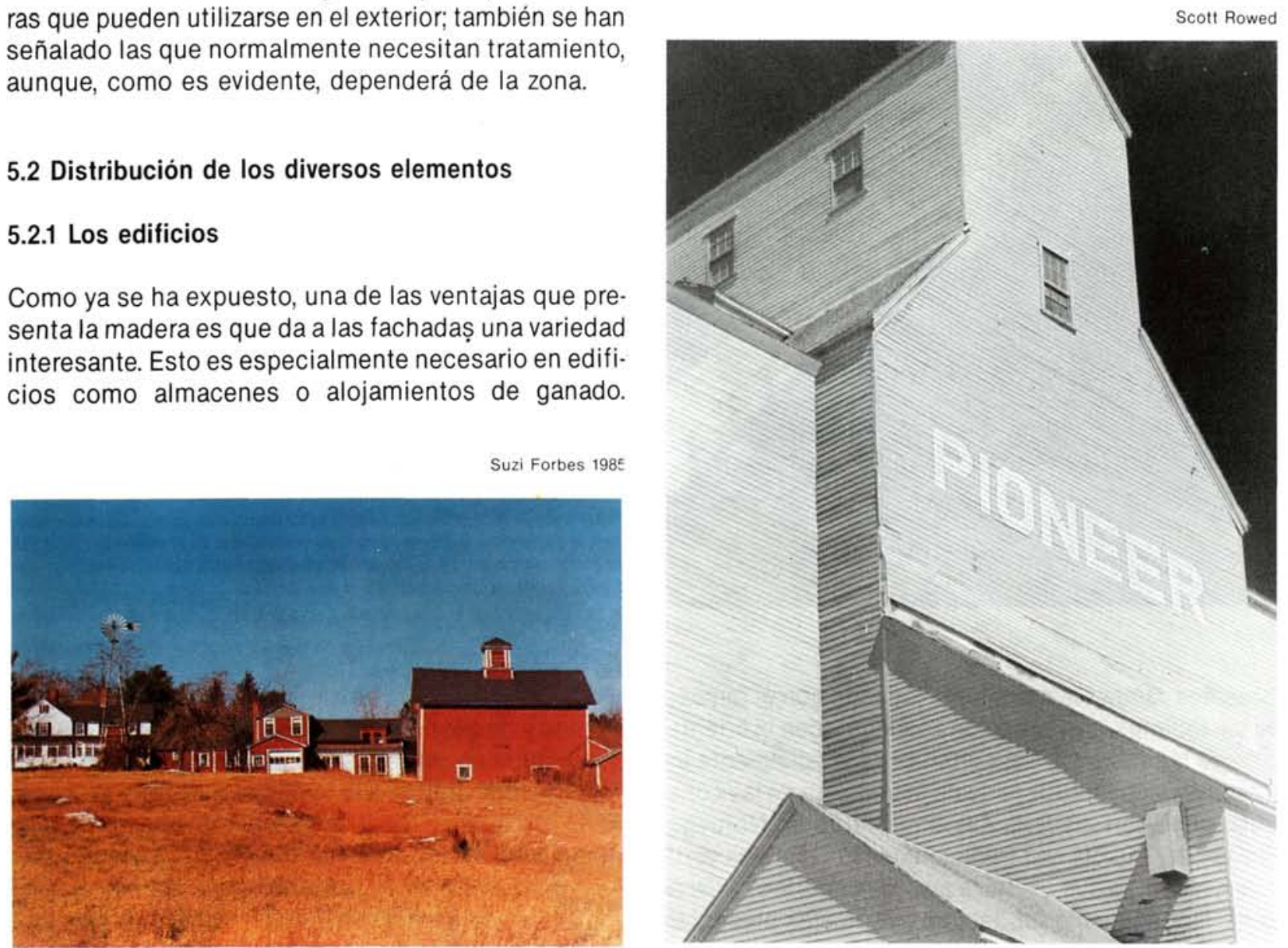

Figs. 6 y 7. Los paños de madera dan a las fachadas una cierta variación que rompe la monotonia en las grandes superficies, solucionando a veces los problemas de escala. 

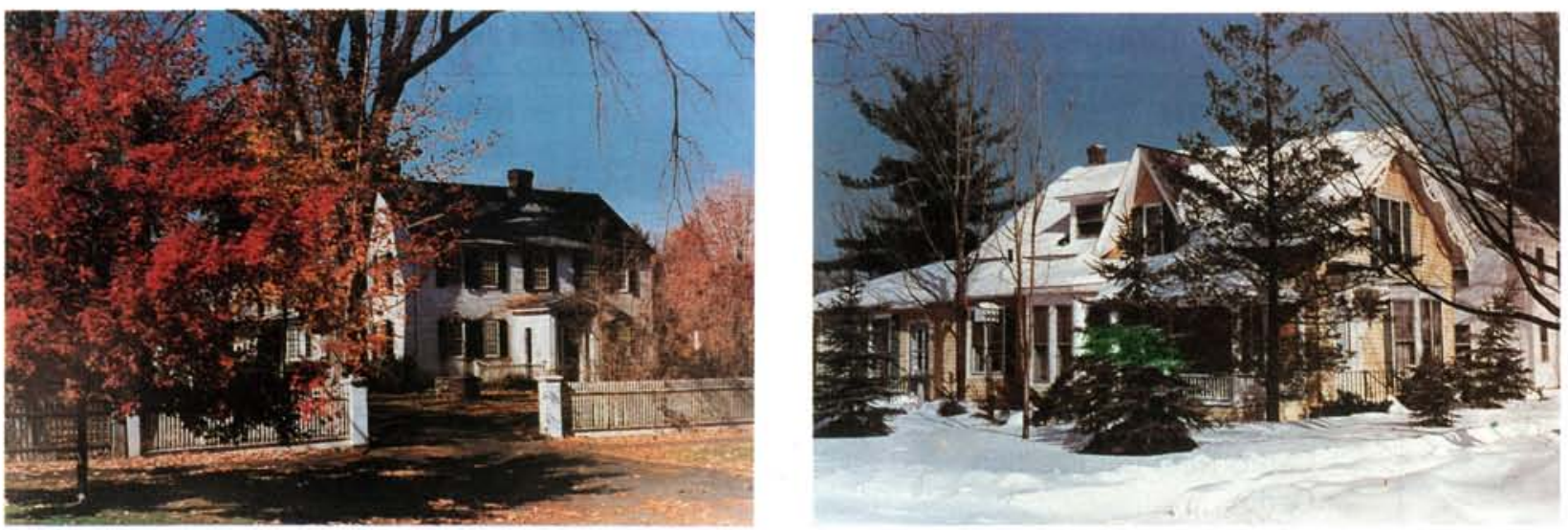

Figs. 8 y 9. La utilización de madera para las viviendas puede contribuir a dar empaque o un cierto aire señorial. Suzi Forbes 1985

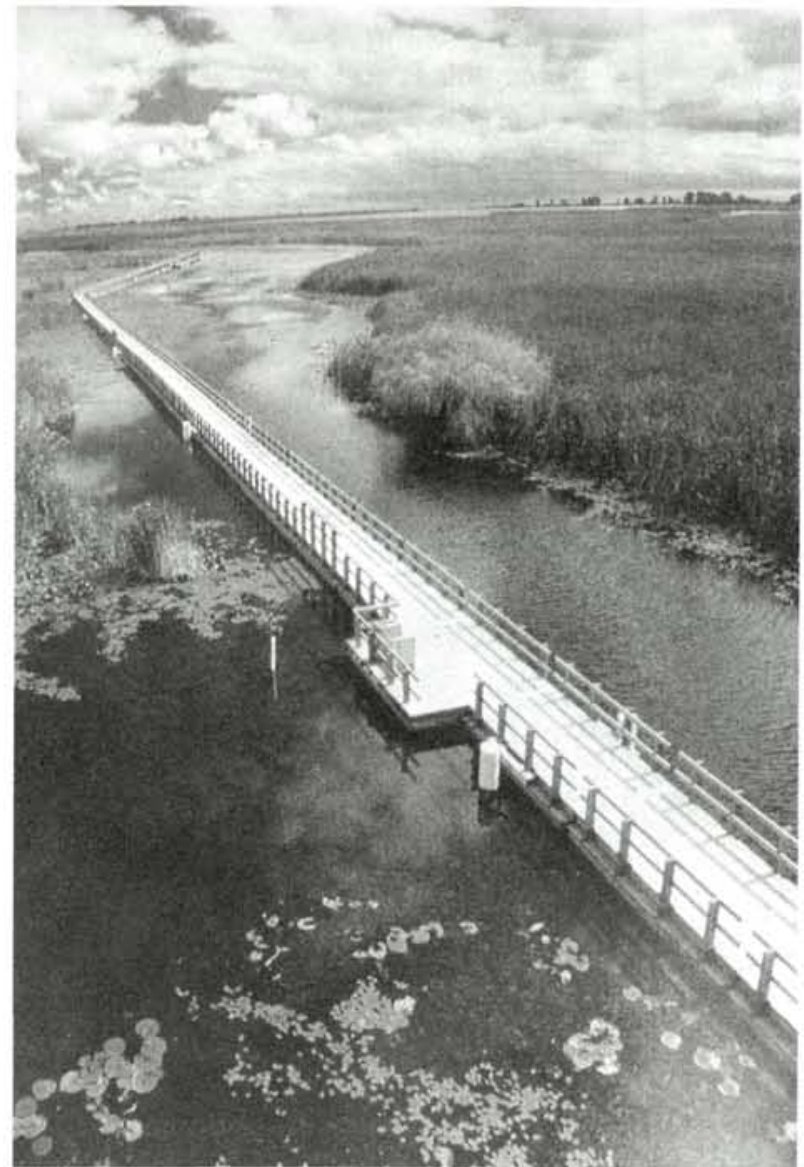

Podemos romper la monotonia jugando con el tamaño de los tableros, con el tipo de acabado y con la orientación de los tableros. Esta última es especialmente interesante, y constituye parte de la tradición de las construcciones con madera. Asi, en el norte de Noruega, Finlandia y Suecia son tradicionales los tableros verticales, mientras que en Suiza abundan más los horizon. tales. Normalmente los tableros verticales presentan algunas ventajas, como son un mejor drenaje y que permite mover la madera. No obstante, la elección entre
Fig. 10. En zonas donde exista abundancia de vegetación y otros elementos naturales, uno de los pocos materiales que conservan la calidad visual es la madera, como éste que muestra la figura. La diferen. cia podria ser grande si el puente fuera metálico o de hormigón. Photo/Graphics

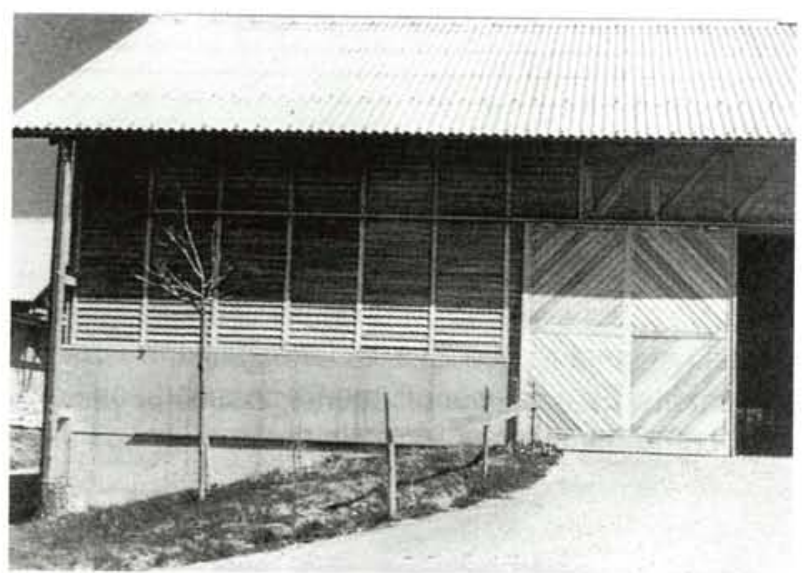

Fig. 11. En la fotografia se puede ver cómo la variación de materiales puede contribuir a disminuir el efecto escala; éste además se ve dis. minuido también por la diferente orientación de los tableros, que dan a esta fachada un bonito acabado. Dolby et al 1988.

uno u otro dependerá de los factores de detalle, de claveteado y de gusto estético. Por ello, en países con po. ca tradición en madera suele ser más normal el tablero horizontal, debido a la facilidad que tiene de claveteado. Un ejemplo de juego en direcciones de los tableros puede verse en la fig. 11. Otra de las ventajas de las construcciones en madera es que las estructuras pueden también tener una función estética. Asi los postes, cartelones, etc., pueden dar un rico contraste en la fachada. 

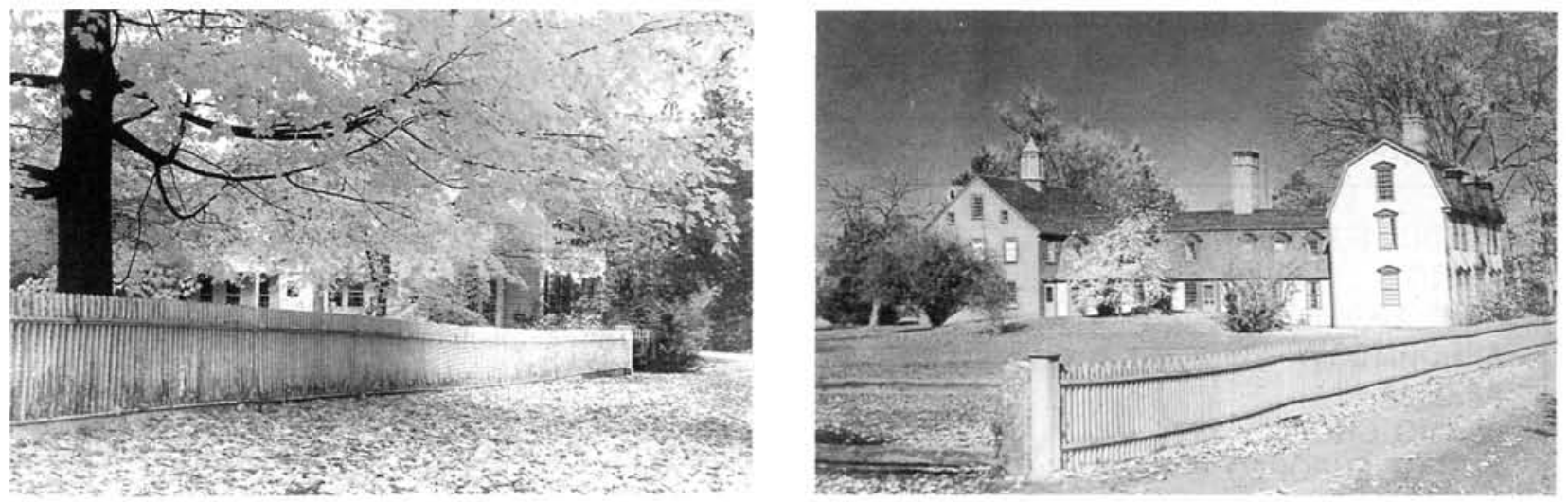

Suzi Forbes 1985

Figs. 12 y 13. La utilización de la madera, como elemento de cierre, presenta interesantes caracteristicas estéticas. Por una parte disminuye el efecto escala, y por otra la falta de uniformidad. Véanse en estas fotografias las ondulaciones de la valla, dan un aspecto natural.

El juego que es posible hacer con los detalles, orientación de las tablas en puertas, sistemas de ventilación en lamas o simplemente agujereados, dan un carácter rústico y campero que guarda una relación inmediata con el paisaje. Por eso es muy importante cuidar los acabados, de forma que los detalles enriquezcan el edificio.

\subsubsection{Instalaciones adyacentes y obras accesorias}

Las construcciones en madera suelen entonar muy bien con la vegetación, y por lo mismo con el resto del paisaje. Desde este punto de vista la vegatación sirve como elemento de conexión entre el edificio y el resto del entorno. Pero también sirve como elemento de co. nexión entre las diversas instalaciones adyacentes y el edificio, pudiendo dar una nota de uniformidad o de contraste.

Los porches. Éste es uno de los elementos que en general suele causar un elevado efecto negativo, por lo que la utilización de la madera presenta muchas ven. tajas. Asi, la utilización de postes y elementos rústi$\cos$ de madera puede resultar muy económica y bas. tante agradable a la vista, frente a los usuales de es. tructura metálica y cubierta de fibrocemento que nos recuerdan a una industria sucia.

Los cerramientos. Los elementos de cierre o limite suelen ser caracteristicos de cada zona, por lo que dependerá de las tradiciones del lugar. Por ejemplo, son típicas las vallas de granito gris en la sierra norte de Madrid; en otros lugares suelen ser más adecuados los cerramientos de madera, por ejemplo de esta forma la guia de "Farm Buildings in Peak National Park" 1981, recomienda los cierres de madera.

Si en la zona no hay una arquitectura vernácula, o si ésta se ha perdido ya, normalmente los cierres de madera suelen resultar estéticos (Figs. 12 y 13).
No obstante, en este elemento pesa más el problema funcional. A veces, puede ser positivo poner dos tipos de cerramientos: uno por las zonas más visibles y otro por el resto.

\section{ESTUDIO DE LOS COMPONENTES ESTÉTICOS DE LA CONSTRUCCIÓN Y EL PAISAJE}

\subsection{La forma, la escala, la linea y el color}

La forma: La forma externa del edificio nos va a condicionar una gran parte del impacto. Pero esta forma viene a su vez condicionada por la estructura. En la fig. 1 aparecen los tipos de estructuras más utilizados en Europa, para las construcciones de madera.

La escala: En las construcciones de madera, el simple cambio de orientación en los tablones puede disminuir el efecto escala.

La linea: En nuestro caso, al utilizar madera podemos crear ciertas líneas en el edificio con la orientación de los tablones. La madera puede atenuar las formas rigidas de algunos diseños, ya que el efecto línea, dado normalmente por el contraste con el fondo, se reducirá al confundirse la instalación con el paisaje adyacente.

El color: Los colores que poseen las maderas son todos cálidos. No obstante, hay una gran diferencia entre unas maderas y otras. Incluso entre el mismo tipo de madera puede haber bastante diferencia. Cuando se determina el color en el paisaje, lo más normal es que se haga por las tablas Munssel, que nos dan los tres parámetros del color: croma, tono e intensidad. En las maderas es dificil aplicarlo cuando se ve el color natural, ya que hay una enorme diferencia entre distintas zonas de la madera. No obstante, si estamos a una cierta distancia, podemos definir un color quessea bastante parecido. En el cuadro 4 aparecen definidos por el croma las distintas maderas. 
CUADRO 4. Caracteristicas de textura y color de las maderas

\begin{tabular}{|c|c|c|}
\hline NOMBRE & COLOR & TEXTURA \\
\hline ABEDUL EUROPEO & Blanco a marrón claro & $\mathrm{F}$ \\
\hline ABETO & Blanco a marrón amarillento & M \\
\hline ABURO ABURA & Marrón claro & $\mathrm{F} / \mathrm{M}$ \\
\hline AFRORMOSIA & Marrón claro & F/M \\
\hline AFZELIA & Marrón rojizo & $M / G$ \\
\hline ALAMO, CHOPO & Gris, blanco a crema & F/M \\
\hline ALERCE EUROPEO & Crema rosáceo-marrón & $\mathrm{F}$ \\
\hline ALISO & Blanco & $\mathrm{F}$ \\
\hline AMARANTO & Pardo rojizo & M \\
\hline ANDIROBA & Rosa a rojo marrón & $M / G$ \\
\hline ARCE BLANDO & Crema claro & $F$ \\
\hline ARCE DURO & Blanco crema & $\mathrm{F}$ \\
\hline BALSA & Blanco - rosado & $\mathrm{F}$ \\
\hline BASRALOCUS & Marrón & M \\
\hline BILINGA ALOMA & Amarillo a naranja amarillo & G \\
\hline BOKAPY & Rojo anaranjado & - \\
\hline BOLONDO, ELON & Pardo rojizo & $\mathrm{G}$ \\
\hline BOSSE, EYO & Marrón rosáceo & M \\
\hline BUBINGA & Sienoso rosado & $M$ \\
\hline CAOBA AMERICANA & Marrón rosáceo & $M$ \\
\hline CASTAÑO & Amarillo marrón & M \\
\hline CASTAÑO DE INDIAS & Blanco a crema marrón & $F$ \\
\hline CEDRO & Marrón rosáceo a marrón rojizo & $\mathrm{G}$ \\
\hline CEDRO DEL LIBANO & Marrón claro & M \\
\hline CEDRO ROJO DEL PACIFICO & Rosáceo marrón & - \\
\hline CEREZO & Marrón rojizo a rojo & $\mathrm{F}$ \\
\hline CORAL & Rojo & G \\
\hline DANTA & Marrón rojizo & $\mathrm{F}$ \\
\hline EBANO & Negro & $\mathrm{F}$ \\
\hline EKKI & Rojo obscuro a marrón obscuro & $\mathrm{G}$ \\
\hline FRAMIRE & Amarillo & $M$ \\
\hline FREIJO & Marrón dorado & $M$ \\
\hline FRESNO EUROPEO & Blanco a marrón claro & $M / G$ \\
\hline FRESNO AMERICANO & Gris, Marrón & G \\
\hline GAIAC & Verde oscuro a marrón & $\mathrm{F}$ \\
\hline HAYA & Crema marrón & $\mathrm{F}$ \\
\hline HICKORY & Marrón a rosáceo marrón & G \\
\hline IPE, PALO DE ARCO & Marrón Oliva & - \\
\hline IROKO & Amarillo Marrón & $M$ \\
\hline JARRAH & Rosa a rojo obscuro & M \\
\hline JELUTONG & Blanco a amarillo & $\mathrm{F}$ \\
\hline KAPUR & Marrón rojizo & M \\
\hline KARRI & Marrón rojizo & M \\
\hline KAUVULA & Crema a amarillo & $M / G$ \\
\hline KERUING/GURJUN & Marrón rosáceo a marrón obscuro & $M$ \\
\hline LIMBAIAFARA & Crema a amarillo & M \\
\hline LIMONCILLO & Amarillo limón-verde & - \\
\hline MADERA DE DURAMEN VERDE & Amarillo, verde oliva a marrón & $\mathrm{F}$ \\
\hline MANSONIA & Marrón-marrón oscuro & $\mathrm{F}$ \\
\hline MENGKULANG & Rojo marrón & G \\
\hline
\end{tabular}


CUADRO 4.- (continuación)

\begin{tabular}{|c|c|c|}
\hline NOMBRE & COLOR & TEXTURA \\
\hline MERANTI ROJO CLARO & Rosáceo a rojo & M \\
\hline MERANTI ROJO OBSCURO & Rojo marrón & M \\
\hline MERBAU & Rojo marrón & $\mathrm{G}$ \\
\hline MONGOY & Marrón oscuro con vetas & - \\
\hline NIANGON & Marrón rosáceo & $M$ \\
\hline NOGAL AFRICANO & Marrón amarillento a veces b. obs. & M \\
\hline NOGAL EUROPEO & Marrón gris con bandas obscuras & G \\
\hline NOGAL NEGRO AMERICANO & Marrón obscuro & G \\
\hline NYATOH & Crema rosáceo a marrón rojizo & $\mathrm{F}$ \\
\hline OBECHE, AYUS & Blanco a amarillo pálido & M \\
\hline OKOLA & Marrón rosáceo a rojo obscuro & $\mathrm{F}$ \\
\hline OKUME & Rosáceo marrón & M \\
\hline OLMO & Marrón claro & G \\
\hline OLMO AMERICANO & Crema, rosáceo marrón & G \\
\hline PALISANDRO DE ASIA & Marrón violeta con betas oscuras & M \\
\hline PALO ROSA & Rojo violáceo & - \\
\hline PALO MARFIL & Amarillo & M \\
\hline PANGA O WENGE & Marrón obscuro con jaspeado obscuro & G \\
\hline PICEA CANADIENSE & Blanco a crema amarillo & M \\
\hline PICEA DE SITKA & Rosáceo-marrón & G \\
\hline PINO ALBAR & Amarillo-marrón a rojo marrón & M \\
\hline PINO AMARILLO & Amarillo-marrón a rojo marrón & M \\
\hline PINO CANADIENSE & Crema amarillo a marrón claro & $\mathrm{F}$ \\
\hline PINO DE MONTERREY & Amarillo a crema marrón & $M$ \\
\hline PINO MARITIMO & Crema marrón a amarillo & $M / G$ \\
\hline PINO MELIX & Rosáceo-marrón & G \\
\hline PINO OREGON & Naranja marrón & M \\
\hline PINO PARANA & Amarillo marrón con betas rojo bril & $\mathrm{F}$ \\
\hline PINO SILVESTRE & Crema, marrón rojizo, marrón & G \\
\hline PLATANO EUROPEO & Rojo marrón & $\mathrm{F}$ \\
\hline RAMIN & Blanco a amarillo pálido & $\mathrm{F}$ \\
\hline ROBLE BLANCO AMERICANO & Amarillo pálido a marrón & M \\
\hline ROBLE DE TASMANIA & Crema rosáceo a marrón & G \\
\hline ROBLE EUROPEO & Amarillo marronáceo & $M / G$ \\
\hline ROBLE JAPONES & Amarillo pálido & M \\
\hline ROBLE ROJO & Amarillo marrón con matices & M \\
\hline SAMANGUILA & Marrón rosado & M \\
\hline SAPELI & Rojo marronáceo con bandas & M \\
\hline SAUCE & Rosa claro a blanco & $\mathrm{F}$ \\
\hline SICOMORO & Blanco a blanco amarillento & $F$ \\
\hline TECA & Marrón dorado, a veces manchas obs. & M \\
\hline TEJO & Rosáceo-blanco & $\mathrm{F}$ \\
\hline TILO & Blanco crema & $\mathrm{F}$ \\
\hline TOLA BLANCA & Amarillo marrón & M \\
\hline TRAMA/KALUNGI & Rojo marrón & M \\
\hline TSUGA & Crema marrón & $\mathrm{F}$ \\
\hline URUNDAY & Marrón & - \\
\hline UTILE & Marrón rojizo & M \\
\hline VIROLA & Rosáceo marrón crema & M \\
\hline
\end{tabular}




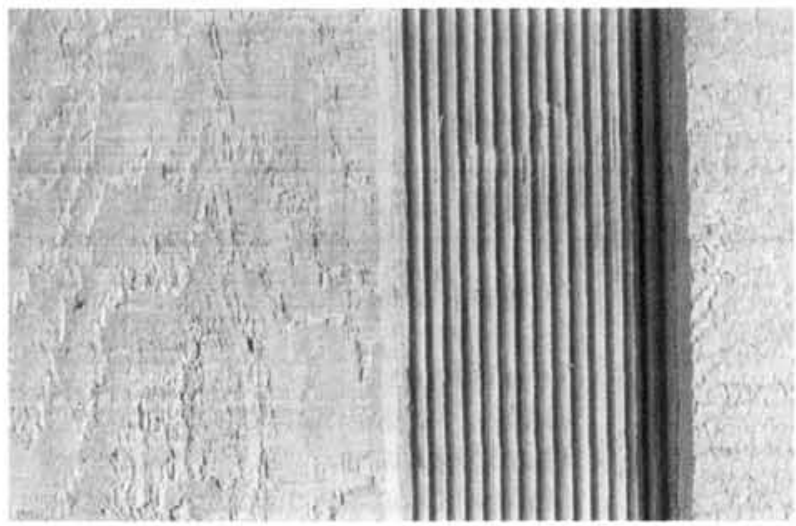

Fig. 14. El acabado y los tratamientos especiales (ranuras) modifican la textura final. En la fotografía tenemos el acabado en aserrado tos. co y las ranuras definidas por: forma en $U$, profundidad $6 \mathrm{~mm}$, espa ciamiento 30,5 mm, y anchura $25 \mathrm{~mm}$. American P. Association 1983.
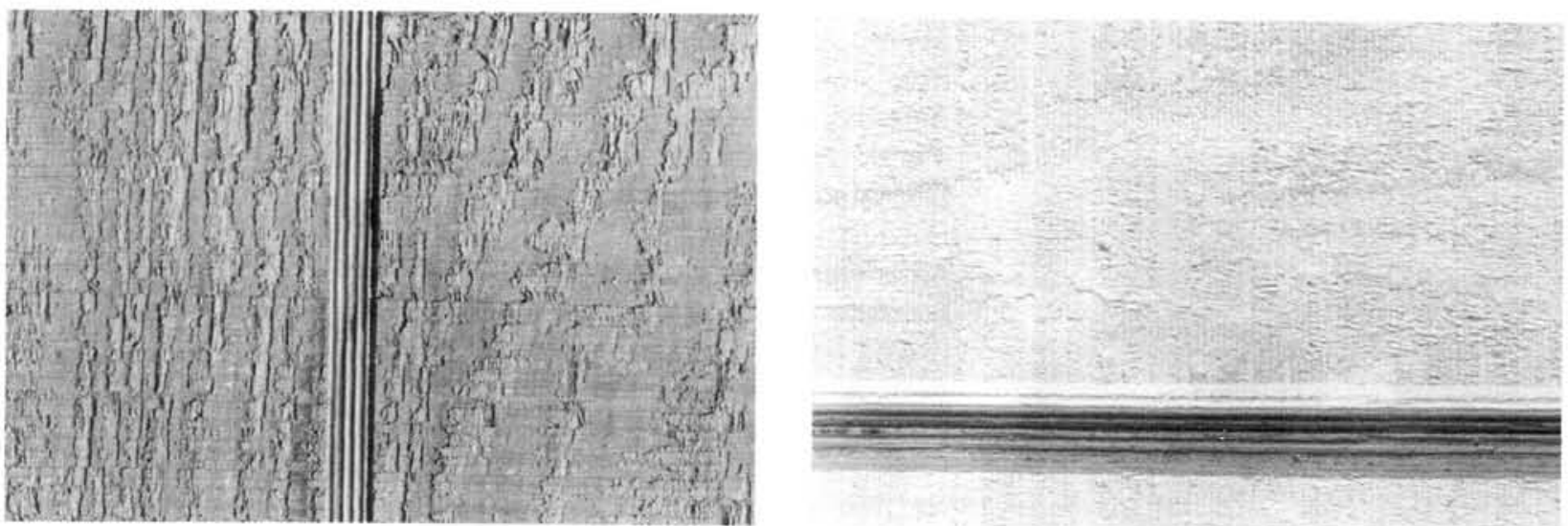

American P. Association 1983

Figs. 15 y 16. La textura final viene definida por: la madera, textura del acabado (lijado, etc.), textura de tratamiento (ranuras) y textura dada por la colocación de los tableros. Por lo que se refiere al acabado vemos en la Fig. 15 aserrado tosco y en la 16 un lijado grueso.
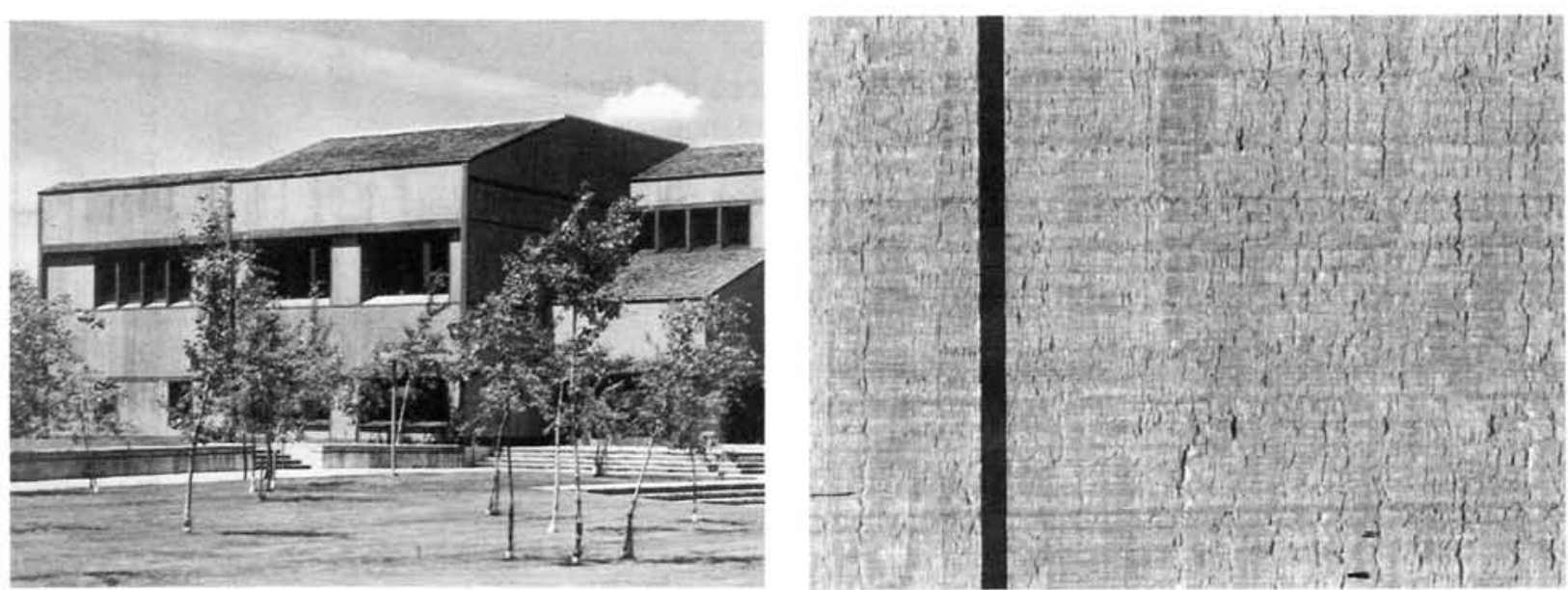

Figs. 17 y 18. En la Fig. 17 aparece un detalle de la madera utilizada en la instalación de la 18. En función de la distancia al edificio podremos apreciar un tipo de textura u otro. American P. Association 1983 
Aparte de los colores naturales se dispone, en el mercado, de una amplia gama de pinturas para maderas que nos permitirán, desde el punto de vista estético, poder tener más posibilidades.

\subsection{La textura}

De los elementos convencionales, la madera es el material que, con diferencia, más posibilidades de textura tiene. En este apartado estudiaremos únicamente el grano de la textura creado por las diferentes posibilidades que nos presenta la madera; Io llamaremos sencillamente textura.
En las construcciones de madera la textura dependerá de:

1. Textura de la propia madera. Se distinguen cinco tipos de textura: Gruesa, Gruesa-Media, Media, MediaFina, y Fina. Esta textura puede enmascararse con el tipo de acabado.

2. Textura dada por el acabado. Estará en función del lijado que se dé a la madera. Podemos distinguir 9 tipos de acabados: Rayado, Aserrado grueso, Aserrado medio, Aserrado fino, Lijado grueso, Lijado medio, Lijado fino, Escobillado y de superficie lisa. Algunos de éstos se pueden ver en las figs. de la 14 a la 22. Nor-
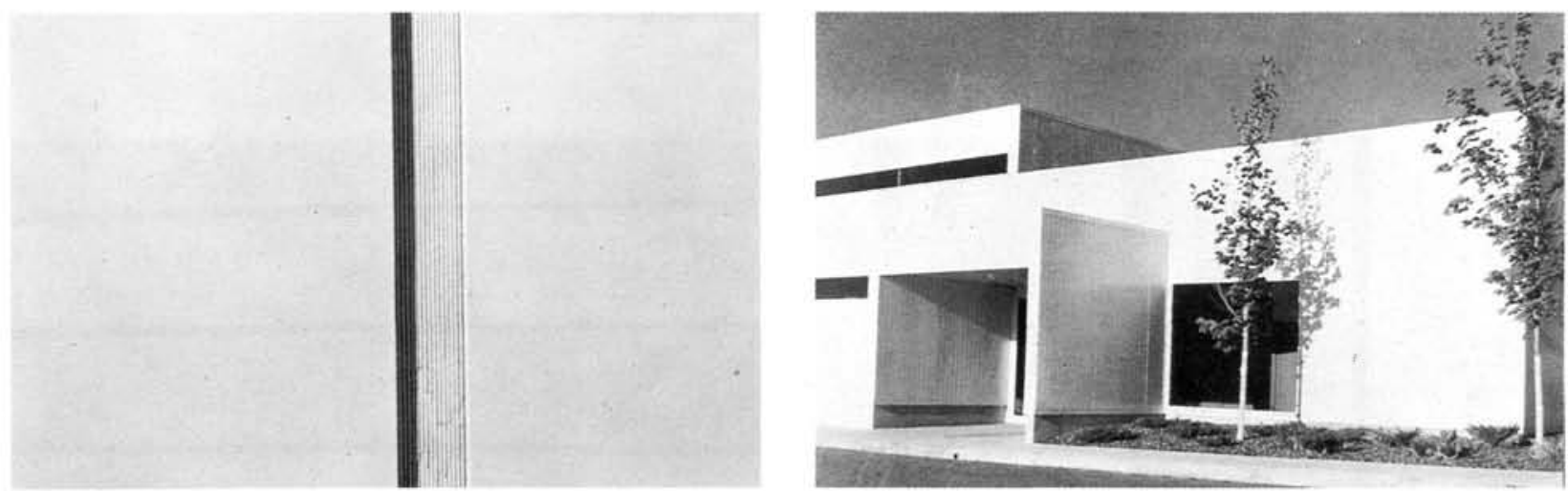

American P. Association 1983

Figs. 19 y 20. La Fig. 19 corresponde a la madera utilizada en la 20. Aqui la textura de acabado es de superficie lisa con ranuras. Las ranuras son muy utilizadas en los contrachapados para crear juegos de sombras muy interesantes desde el punto de vista estético.

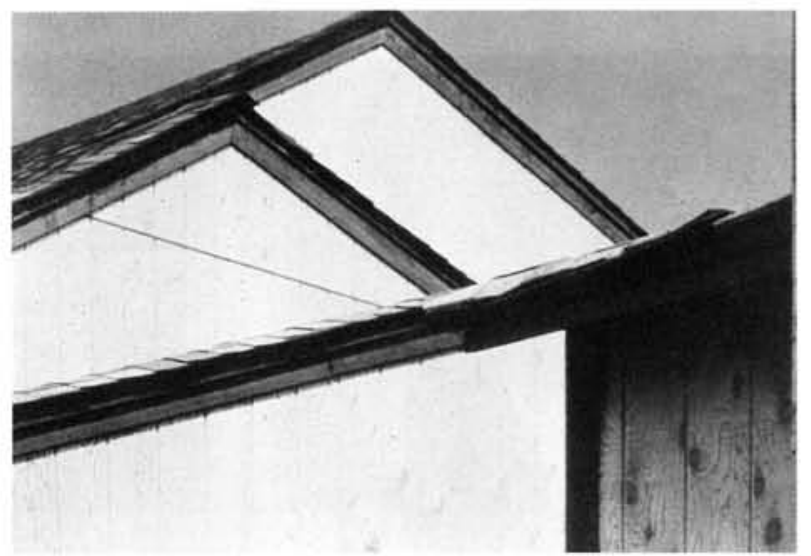

American P. Association 1983

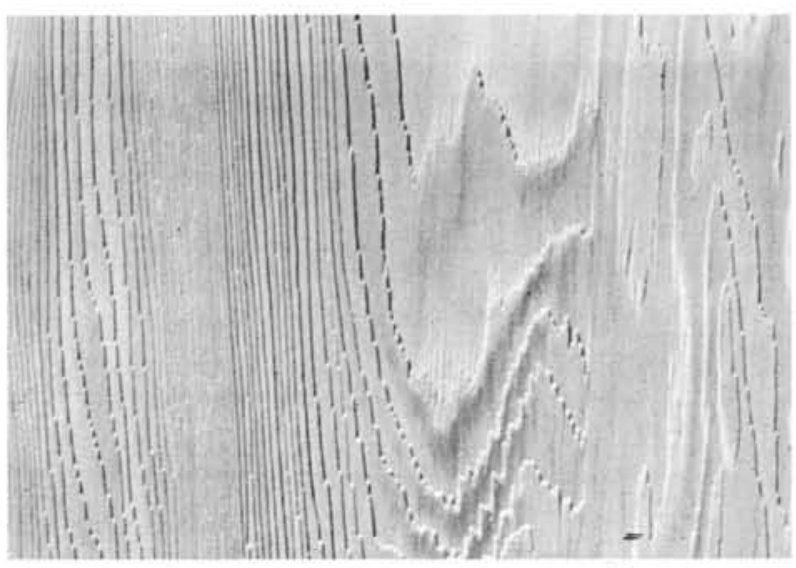

$-$

Figs. 21 y 22. La Fig. 21 es un detalle de la madera de la 22, en donde se utilizó un acabado de escobillado, también llamado de fibra en relieve. Como se puede apreciar, con éste se consigue acentuar el diseño natural de la veta. 
malmente sólo se aprecia esta textura a distancias cortas, hasta 10 ó 15 metros aproximadamente.

3. Textura dada por tratamiento especial. Son lo que normalmente se conoce como ranuras o maderas acanaladas. La textura final vendrá dada por:

- Tipo de ranura (en forma de $\mathrm{U}$, en forma de $\mathrm{V}$, etc.)

- Distribución de las ranuras (espaciamiento).

- Profundidad de las ranuras ( $\mathrm{mm}$ que penetra).

- Anchura de la ranura.

Con este tipo de tratamientos se consiguen distintos tipos de sombras, muy interesantes desde el punto de vista estético. Estas texturas se aprecian a distancias cortas-medias, máximo unos 100 metros. Normalmente, se utilizan mucho en los contrachapados.

\section{Textura dada por la colocación de los tableros.}

La orientación de los tableros puede ser: vertical, ho- rizontal o inclinada. A su vez dentro de cada uno de éstos podemos clasificarlos en:

- Tableros juntos. Que pueden estar unidos o solapados; a su vez los solapados pueden ser recto o curvo.

- Tableros separados.

- Tableros cubiertos con listones. Pueden estar cubiertos con listones por delante o por detrás.

- Tableros montados.

- Tableros con rebaje.

Los distintos tipos pueden verse en la figura 2 y en las Figs. 23,24 y 25 . Esta textura puede apreciarse hasta unos 100-150 metros.

Como se aprecia hay un amplio abanico de posibilidades. Además, las tres últimas, es decir, las texturas de acabado, de tratamiento especial y de colocación, no se ven modificadas por las pinturas habituales para madera. En las de acabado hay pinturas que lo modifican y otras que no.

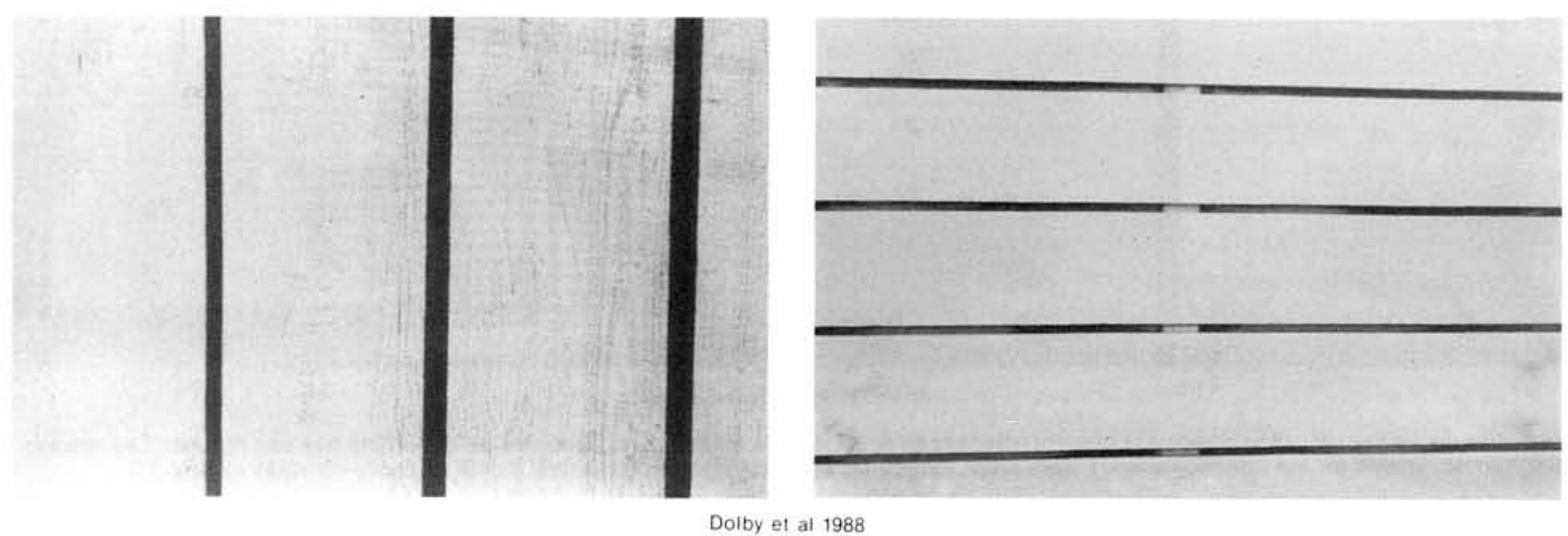

Figs. 23 y 24. La textura dada por la colocacion de los tableros puede ser: vertical, horizontal e inclinada. Dentro de cada una hay varios tipos. Asi en la Fig. 23 aparece un tablero vertical cubierto con listones por detrás; en la 24 se ve un tablero horizontal separado.
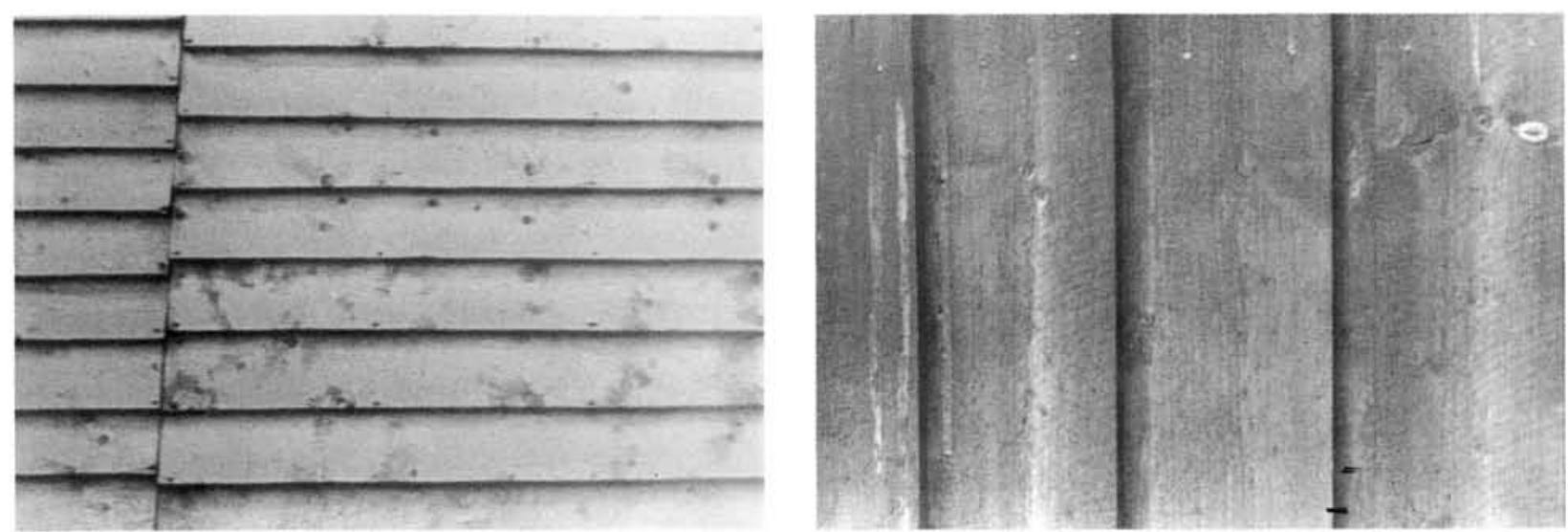

Figs. 25 y 26. En la Fig. 25 se ve la textura de colocación de un tablero junto solapado recto, donde además pueden romperse las lineas horizontales al cambiar la altura de las tablas. En la 26 se observa un tablero con rebajes. Dolby et al 1988 

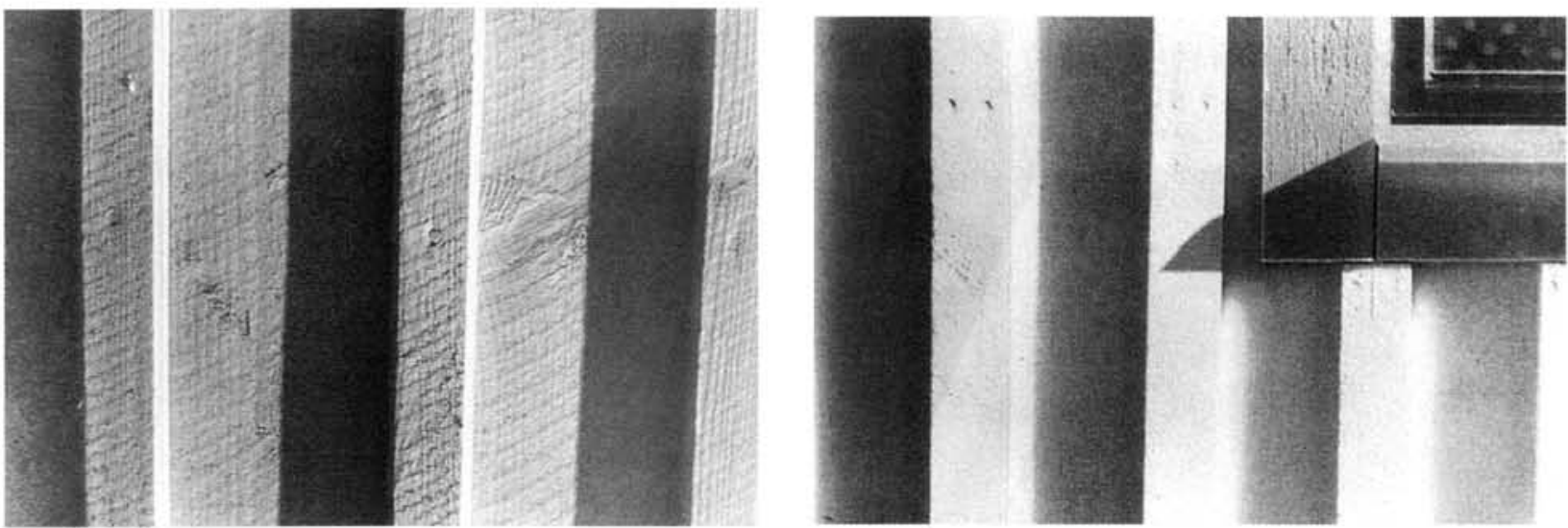

Figs. 27 y 28. En estas fotografias se observa la textura creada por los tableros cubiertos con listones por delante. Las distancias entre los listones, la anchura y grosor de éstos, dan texturas diferentes. Dolby et al 1988

\section{BIBLIOGRAFIA}

ARRIAGA, F. 1986. "Estructuras de madera, análisis de normativa, materiales y tipologias". AITIM. Madrid.

AMERICAN PLYWOOD ASSOCIATION 1983. Madera contrachapada estructural para recubrimiento exterior.

BALBO, P. P. et al. 1979. "Figure nel paesaggio. Proposte per L'edilizia residenziale". Agricultura ambiente. V 1 (3), págs. 31-45.

CULL, S. 1987. "Design Guidance for Farm Buildings". Farm Buildings an Engineering. 3 (3), págs 12-16.

CULL, S. 1986. "Farm Buildings and Planning Control". Farm Buildings and Engineering. Vol. 3. $\mathrm{N}^{\circ} 2$.

DAMM, T. 1982. "Landschaftsbezogenes Bauen in Nordrhe Westfalen". Landtechnik. V 37 (12) págs. 540-541.

DI FACIO, J. 1989. "Designing Agricultural Buildings in Relation to the Landscape". $11^{\circ}$ International Congress on Agricultural Engineering. Land and Water Use, Dodd \& Grace (eds). Balkema. V 2, págs. 1191-1198.

DOLBY, C. et al 1988. "Rural Constructions in Timber". Department of Farm buildings, Lund. Sweden.

MARTINOT, R. 1975. "'Les bâtiments agricoles peuvent is ameliorer le paysage". Tracteurs et Machines agricoles, $n^{\circ} 3$, págs. 159-162.
MENNER, L. 1982. "Landschaftsbezogenes bauen in Bayern”. Lantechnik. V 37 (12) págs. 54-58.

O'FARRELL, F. 1987. "Farm Buildings and Environment". Foras Taluntais. Dublin.

PENFOLD, H. G. 1979. "Landscape and Farm Buildings". Adas Quarterly Review (UK). Págs. 223-230.

PHILLIPS, A. F. 1986. "A Comparative View of Four industrial Buildings". Landscape Research. 11 (1), págs. 29-32.

SHAKESPEARE, R. P. and DODD, V. A. 1989. "A Technique for Assessing the Correct Colour Scheme and As. sociated Landscaping for Buildings in Rural Landscapes". $11^{\circ}$ International Congress on Agricultural Engineering. Land and Water Use, Dodd \& Grace (eds). Balkema. Págs. 1207-1212.

SUZI FORBES. 1985. New England. Crescent Books.

SUNLEY, J. and BEDDING, B. (Ed.) 1985. Timber in Construction. TRADA. London.

VARIOS. 1986. "Wood information". Guide to the use of timber and wood based panel products. TRADA.

VARIOS. 1976. "La madera", Editorial Blume. Barcelona. 